\title{
THE INFLAMMATORY RADICULAR CYSTS HAVE HIGHER CONCENTRATION OF TNF- $\alpha$ IN COMPARISON TO ODONTOGENIC KERATOCYSTS (ODONTOGENIC TUMOUR)
}

\author{
Vladimir Jurisic ${ }^{1}$, Snjezana Colic $^{2}$, Milan Jurisic ${ }^{2}$ \\ University of Kragujevac, School of Medicine, Kragujevc, Serbia'; University of Belgrade Clinic for Oral Surgery, School \\ of Dentistry, Belgrade, Serbia ${ }^{2}$

\begin{abstract}
Summary: TNF- $\alpha$ is a pleiotropic cytokine that is considered as a primary modifier of inflammatory and immune reaction in response to various inflammatory diseases and tumour. We investigated levels of TNF- $\alpha$ in 43 radicular cysts and 15 odontogenic keratocysts, obtained from patients undergoing surgery, under local anaesthesia, and after aspiration of cystic fluid from non-ruptured cysts. TNF- $\alpha$ is elevated in both cysts' fluid, but higher values were found in radicular cysts in comparison to keratocysts. The significantly higher concentration of TNF- $\alpha$ was associated with smaller radicular cysts, higher protein concentration, higher presence of inflammatory cells in peri cystic tissues, and the degree of vascularisation and cysts wall thickness (Mann-Whitney U-test, $\mathrm{p}<0.05$ ). No correlation was found based on these parameters in odontogenic keratocyst, but all cysts have detectable concentrations of TNF- $\alpha$. We here for the first time present that a difference in the concentration of TNF- $\alpha$ exists between these two cystic types.
\end{abstract}

Key words: TNF; Radicular cysts; Odontogenic tumour; Surgery; Cyst size; Hystology

\section{Introduction}

Odontogenic keratocysts (OKC) are one of the commonest bone-destroying lesions of the maxillofacial skeleton. The aggressive behaviour and high recurrence rate of OKC suggests neoplastic potential and promted the World Health Organization Working Group to classify a OKC as a benign tumour with odontogenic epithelium $(1,3,4,23)$. However, there are some controversies regarding the nature of the odontogenic keratocyst. Contrary to this, the radicular cysts are a result of inflammatory processes in the periapical tissues associated with necrotic and infected pulps (24). Humoral and cellular immune responses play a role in the pathogenesis of inflammation as well as in cancer. Based on pleiotropic effects of TNF, it is very interesting to compare data betwen these two types on lesions in the maxilofacial region.

Tumour necrosis factor- $\alpha($ TNF- $\alpha)$ is a cytokine initially identified as a cause of hemorrhagic necrosis in certain tumors $(12,13)$. It is secreted by macrophages, monocytes and NK cells and many other cell types and it exists in two forms. The biological actions of TNF- $\alpha$ was mediated after binding to its specific cell surface receptors, belonging to the TNF receptor superfamily (14). TNF- $\alpha$ mostly triggers apoptosis and necrosis in sensitive tissues and has been linked to osteomyelitis and apical periodontitis, but it can also participate, in skeletal homeostasis, including osteo- clastic formation, and bone resorption in the maxillofacial region. TNF- $\alpha$, among other cytokines, can regulate fibroblast activity and collagen formation through modulation of collagenase activity $(5,7,22,26)$. In addition, TNF- $\alpha$ can induce low dose proliferation of several cells and can be one of the reasons for tumour growth $(13,14)$.

Although there is a significant amount of data about TNF- $\alpha$ expression in radicular cyst and $\operatorname{OKC}(6,16,19)$. Comparison of the TNF- $\alpha$ between radicular cyst and OKC has not be investigated previously. Based on multiple pro-inflammatory effects of TNF- $\alpha$, the aims of this study was to analyze its concentration in these two cystic types regarding clinical symptoms, cystic volume, inflammatory processes, and the presence of cystic wall thickness and vascularisation based on radiographic and on histological examinations as well.

\section{Material and methods}

\section{Patients}

Forty-three radicular cysts and fifteen odontogenic keratocysts were obtained from patients undergoing surgery at the Oral Surgery Department, University of Belgrade, School of Dentistry. The cysts were surgically enucleated under local anesthesia. The mucoperiostal flap was raised, and, if necessary, a bur was used to remove bone under irrigation with sterile saline solution, avoiding injury to the 
cystic wall. The cystic fluid was aspirated from non-ruptured cysts (any samples contaminated with blood were excluded), then immediately centrifuged (3000 RPM for 20 minutes) to remove cells, and the supernatant was stored at $-70{ }^{\circ} \mathrm{C}$ until used for assays. After the enucleation, one section of cystic wall was taken for histopathological evaluation. The final diagnosis of the cysts was confirmed on the basis of clinical, radiographic, and histological examinations. The size of the cysts was calculated as the mean values of the largest dimension (line a) on radiography and the dimension perpendicular to it (line b) using the formula $(a+b) / 2$. Cysts were divided into the following groups with mean sizes below $2 \mathrm{~cm}$, from 2 to $3 \mathrm{~cm}$ and over $3 \mathrm{~cm}$. The patients had no history of infection in the cystic lesions and they had not taken antibiotics or long-term anti-inflammatory medications during the preceding 2 months. No orocystic communications were clinically detected before surgery. The local human ethics committee approved the study protocol. After receiving information about the character and purpose of the study, the subjects gave written consent for participation.

\section{Determination of TNF- $\alpha$}

The concentrations of TNF- $\alpha$ in the cystic fluids were measured by ELISA, obtained from Diaclone, Besancon, France, according to the manufacturer's recommended protocol. The concentrations of TNF- $\alpha$ in the samples were mathematically calculated from the standard curve obtained from different dilutions of known concentrations of rh TNF- $\alpha$ in the original assay. Detection was in the range of 15.6 to $1000 \mathrm{pg} / \mathrm{ml}$. Absorbance was measured with a microplate reader at $450 \mathrm{~nm}$ (Berhringer EL 311, Germany).

\section{Determination of proteins}

Proteins were determined semiquantitatively and results were expressed as a level of opalescence (low, intermediate and high).

\section{Histomorphometric study}

The material used in this study consisted of peri-cystic biopsy tissues. The tissues were removed under local anesthesia during routine cyst surgery and immediately fixed in $10 \%$ neutral buffer formalin at room temperature. The tissue blocks were sliced into $3 \mu \mathrm{m}$ thick section for routine histological examinations after staining with hematoxylin and eosin (H\&E). A minimum of three sections in each sample was used to assess the presence of the inflammatory cells, the degree of vascularisation and the degree of epithelial proliferation. Briefly, each specimen was graded at $400 \mathrm{x}$ magnification as: grade I (slight) less then 10 inflammatory cells per field; grade II (moderately inflamed), 10-50 inflammatory cells per field, and grade III (highly inflamed) more then 50 inflammatory cells per field. Grading of each specimen was based on the average inflammatory cell number in three consecutive microscopic fields starting from the epithelial-connective tissue border and proceeding gradually deeper into the lamina propria. The degree of vascularisation was characterized as low (below 10 blood vessels $/ \mathrm{mm}^{2}$ ), as moderate (11 to 15 blood vessels $/ \mathrm{mm}^{2}$ ) and as high (over 15 blood vessels $/ \mathrm{mm}^{2}$ ). The degree of epithelial proliferation in the cyst walls was analyzed in respect to the number of the epithelial layer cells and described as low, moderate and high. Cyst wall thickness was described as thick (over $1.5 \mathrm{~mm}$ ) and non thick (below $1.5 \mathrm{~mm}$ ) based on histological findings presenting on more then $2 / 3$ sections.

\section{Statistical analysis}

A statistical significance between observed parameters analyzed in the study was calculated by Mann-Whitney U-test and ANOVA using Excel and SPS software for windows 2000 on Compaq computer (Evo 170, USA).

\section{Results}

This investigation demonstrated the presence of TNF- $\alpha$ in all cysts (Fig. 1b). However, significant higher concentrations of TNF- $\alpha$ were found in radicular cysts $(99.3+/-27.3$ $\mathrm{pg} / \mathrm{ml}$ of cystic fluid) in comparison to odontogenic keratocysts $(29.2+/-1.5 \mathrm{pg} / \mathrm{ml}$, Mann Whitney U-test, $\mathrm{p}<0.05)$. When we analyzed TNF- $\alpha$ in respect to the cystic volume, different results were obtained. Higher values of TNF- $\alpha$ were associated with smaller radicular cysts (Fig. 2a) while keratocysts (Fig. 2b) did not show any changes in relation to the cystic volume. The influence of protein concentration in the cystic fluid analyzed at the level of cystic opalescence showed that radicular cysts (Fig. 3a), containing higher protein concentration and higher opalescence, have a higher TNF- $\alpha$ concentration, while this parameter does not show any influence in keratocysts (Fig. 3b). We further investigated the role of cyst walls on TNF- $\alpha$ concentration.

Tab. 1: Cyst characteristics.

\begin{tabular}{|l|r|c|}
\hline $\begin{array}{l}\text { Cyst } \\
\text { type }\end{array}$ & $\begin{array}{c}\text { Radicular } \\
\text { cyst }\end{array}$ & $\begin{array}{c}\text { Odontogenic } \\
\text { keratocyst }\end{array}$ \\
\hline Cyst number & 43 & 15 \\
Thick wall & $77.77 \%$ & $30 \%$ \\
Non thick wall & $22.33 \%$ & $70 \%$ \\
Degree of inflammation & $7.00 \%$ & $56.33 \%$ \\
$\quad$ Slight & $18.60 \%$ & $36.33 \%$ \\
Moderate & $74.40 \%$ & $7.33 \%$ \\
$\quad$ Pronounced & $8.33 \%$ & $61 \%$ \\
Degree of vascularisation & $22.22 \%$ & $23 \%$ \\
Low & $69.45 \%$ & $16 \%$ \\
Intermediate & & \\
$\quad$ High & & \\
Degree of epithelial & & \\
proliferation & $21.10 \%$ & $20 \%$ \\
Low & $37.20 \%$ & $46.70 \%$ \\
Moderate & $41.70 \%$ & $33.30 \%$ \\
\hline High & \multicolumn{2}{|c}{} \\
\hline
\end{tabular}




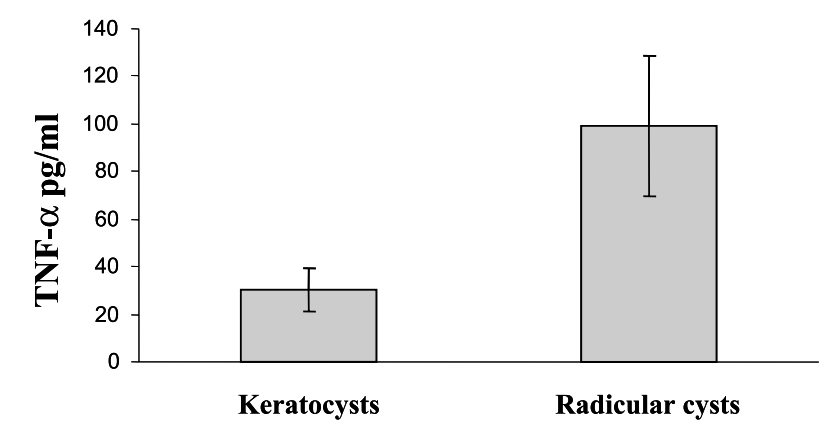

Fig. 1: Mean values of TNF- $\alpha$ concentration in radicular cysts $(n=43)$ was significantly higher in comparison to keratocysts $(\mathrm{n}=15)($ Mann-Whitney U-test, $\mathrm{p}<0.05)$.

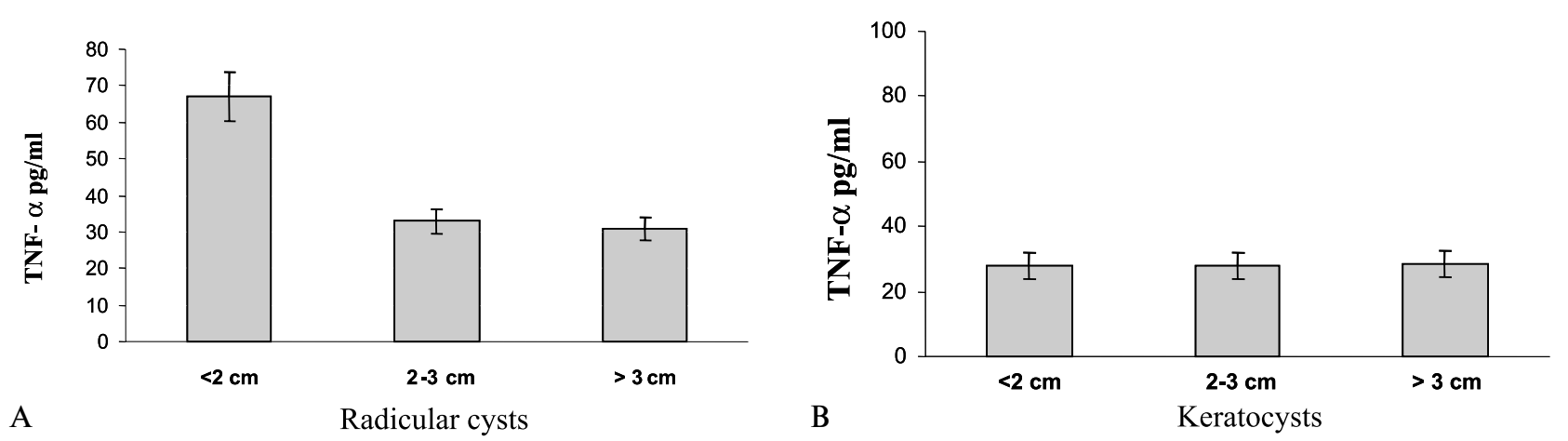

Fig. 2: TNF- $\alpha$ concentration depending on cystic volume in radicular cysts (A) and keratocysts (B).
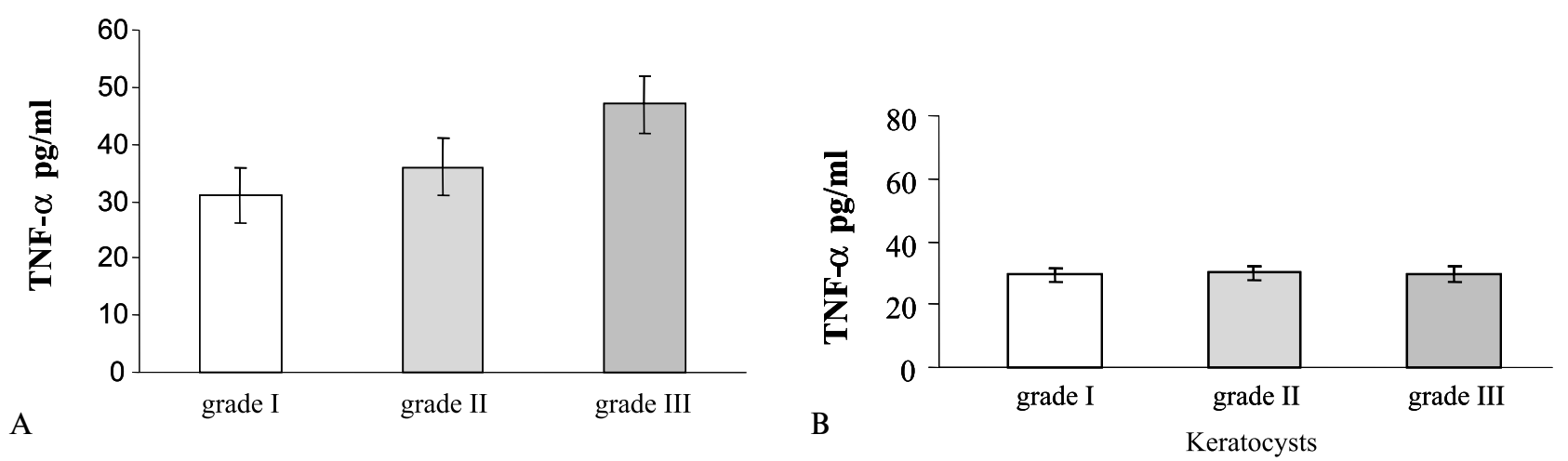

Fig. 3: TNF- $\alpha$ concentration was significantly increased depending on the degree of fluid opalescence in radicular cysts (A). No correlation was found in keratocysts (Mann-Whitney U-test, p>0.05) (B).

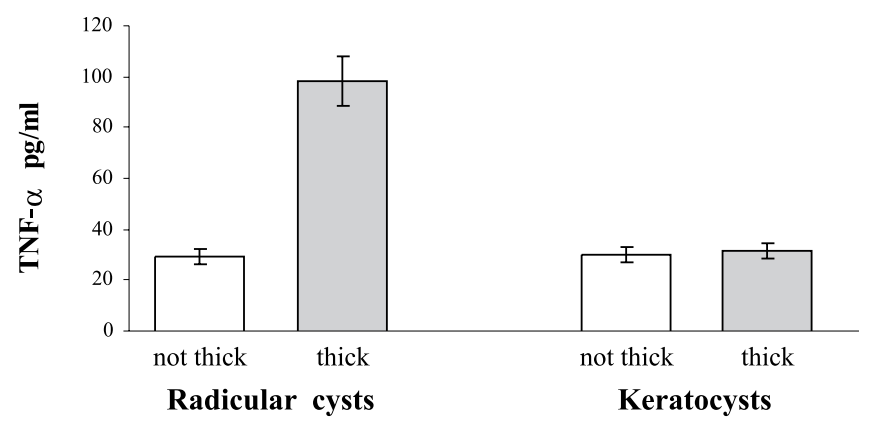

Fig. 4: TNF- $\alpha$ concentration was significantly higher in radicular cysts with thick walls in comparison with non-thick walls (Mann-Whitney U-test, $p<0.05$ ). There is no statistical difference in keratocysts (Mann-Whitney U-test, $p>0.05$ ). 
Radicular cysts with thick cystic walls have significant higher values (Mann Whitney U-test, $\mathrm{p}<0.05)$ of TNF- $\alpha(88+/$ $12 \mathrm{pg} / \mathrm{ml})$ in comparison to non-thick cystic walls $(29.5$ $+/-9 \mathrm{pg} / \mathrm{ml}$ ). Further, we estimated the role of cystic walls on the production of TNF- $\alpha$ in respect to the presence of inflammatory cells, the degree of epithelial proliferation and the degree of vascularisation on histological H\&E section. TNF- $\alpha$ significantly increases in cysts with a higher degree of cell infiltration (Mann-Whitney U-test, $\mathrm{p}<0.05$ ) in comparison to slighty (Fig. 5a). Also TNF- $\alpha$ positively cor- related with higher vessel count in the cystic wall (Fig. 7) of radicular cysts (Mann-Whitney U-test, $\mathrm{p}<0.05$ ). However, the number of inflammatory cells rather than epithelial characteristics in raducular cysts (Fig. 5a, 6a) showed a stronger association with increased TNF- $\alpha$ (ANOVA, $\mathrm{p}<0.05)$. Contrary to this, all keratocysts have a similar concentration of TNF- $\alpha$ irrespective of the cystic wall (Fig. 4), the number of inflamed cells the epithelium proliferation (Fig. 6b), and presence of vascularisation (Fig. 7) having been analyzed histologically.
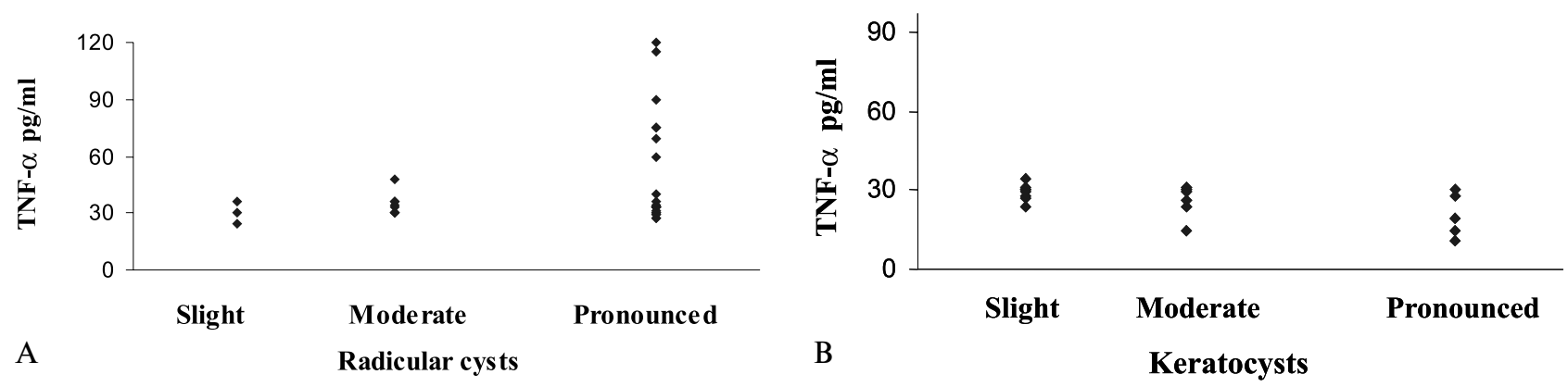

Fig. 5: The individual values of TNF- $\alpha$ concentration in cyst fluid in respect to the number of inflammatory cells presenting in cyst walls on radicular cysts (A) and keratocysts (B). TNF- $\alpha$ was significantly incresed in radicular cysts with pronounced presence of inflammatory cells in comparison with slightl (Mann-Whitney U-test, $\mathrm{p}<0.05$ ). No correlation was found in keratocysts based on these criteria (Mann-Whitney U-test, $p>0.05$ ). ANOVA shows a significant difference between these two cyst types $(\mathrm{p}<0.05)$.

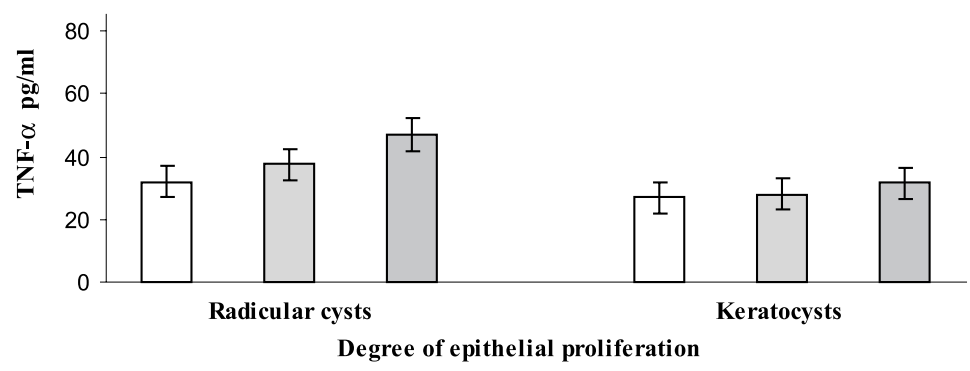

Fig. 6: Concentration of TNF- $\alpha$ in respect to the degree of epithelial proliferation. Open bar reflects low, grey reflects moderate and shaded bars reflect high epithelial hyperplasia. There is no significant difference regarding these parameters (ANOVA, $\mathrm{p}>0.05$ ).

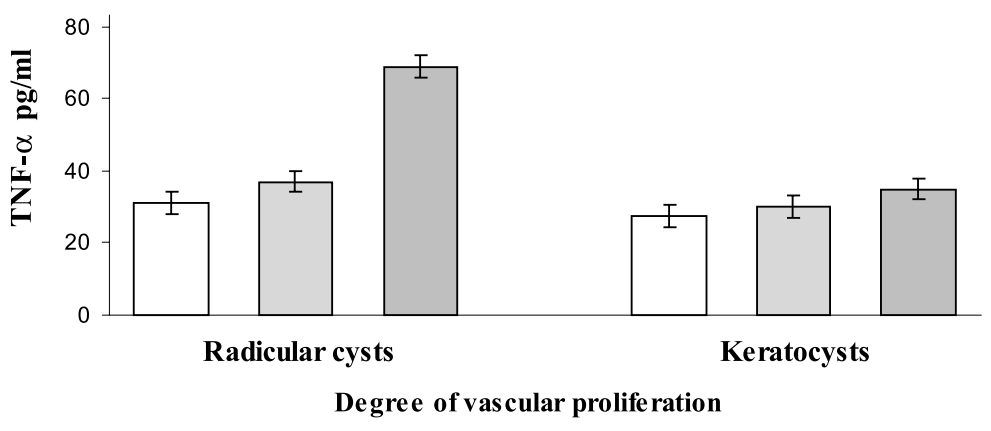

Fig. 7: TNF- $\alpha$ concentration in cystic fluid in respect to the degree of vascularization. Open bar reflects low (below 10 blood vessels $/ \mathrm{mm}^{2}$ ), grey bars moderate (11 to 15 blood vessels $/ \mathrm{mm}^{2}$ ) and dark bars high vascularization (over 15 blood vessels $/ \mathrm{mm}^{2}$ ). Significant difference exists between low and high vascularization in radicular cysts (Mann-Whitney U-test, $\mathrm{p}<0.05)$. 


\section{Discussion}

The role of cytokines in inflammation and bone remodeling has been extensively investigated during the last decade $(5,7,22,26)$. Previous literature data indicated that TNF- $\alpha$ among other cytokines, can be closely associated with ethiopathogenesis of radicular cysts $(6,16,19)$. Our investigation gives new results by showing a different concentration of TNF- $\alpha$ in cystic fluid between two cyst types in the maxillofacial skeleton. These data reflect the ethiopathology of radicular cysts as inflammatory and shaw that there are results in infection and necrosis of the dental pulps in carious teeth and cystic tissue (15). The growth of radicular cysts is accompanied by local bone destruction, tissue osteolysis and accumulation of different cells in the cystic epithelium. During this dynamic inflammatory process, TNF- $\alpha$ was accumulated in the cystic fluid. In vitro studies showed that polymorphonuclear leukocytes isolated and cultured from chronically inflamed sites of bone resorption can produce inflammatory cytokines, such as TNF- $\alpha$ (2).

We here for first times report that TNF- $\alpha$ is more accumulated in radicular cysts than in keratocysts. The smaller cysts contained a higher concentration of TNF- $\alpha$, indicating that these cytokines are actively secreted into the cystic fluid. Furtheremore, we investigatated the role of the cystic epithelium on the amount of the released TNF- $\alpha$ into the cystic fluid in these two cystic types. Some studies based on cell culture system or histopathology examination, have indicated a significant role of TNF- $\alpha$ in inflammation, periapical exudates, bone resorption and other periodontal disease, explaining the mechanism of these processes. Based on the consideration that radicular cysts contained a highly significant number of inflammatory cells, including leukocyte, macrophages, $\mathrm{CD} 3+$, and CD $8+$ cells $(8$, $21)$ as well as inflammatory cytokines, chemotactic cytokine and other mediators in different levels $(2,8,10,20,21)$, we can explain our results.

We here correlate TNF- $\alpha$ concentration not only depending on cysts wall thickness but also on the number of proinflammatory cells in the cyst wall, the degree of vascularisation $/ \mathrm{mm}^{2}$ and other epithelium characteristics on the histology section. The histomorphometric analyses in this study showed that the majority, i.e 35 (77\%), of all 43 radicular cysts have a thick wall, contrary to only 5 (30\%) odontogenic keratocysts from all the 15 examined, indicating that different cyst walls exist in these two cyst types. These findings are in correlation with futher results concerning enumeration of inflammatory cells in cyst walls, indicating that from all investigated radicular cysts, the majority $(74.4 \%)$ have a pronounced acount of infiltrated cells in cyst wells, contrary to keratocyst, which usually have slight infiltration (53.3\%). Both of these findings were closely associated with the amount of produced TNF- $\alpha$ and can be a major reason for the increase of TNF- $\alpha$ in radicular cysts. Only activated macrophages in comparison to other cell subsets, including fibroblasts also presenting in inflammatory cyst walls, are a major source of TNF- $\alpha$. It has been reported previously that epithelial cells after in vitro exposure to TNF- $\alpha$ produced many other cytokines, like GM-CSF, which have an additional role in inflammation, cell adhesion and cyst formation. These produced cytokines might be inducible rather than constitutive, when epithelial cells receive various kinds of stimulation, which is the situation in radicular cysts $(20,25)$. In addition, TNF- $\alpha$ can act as a pro-inflammatory cytokine and stimulate bone resorption $(9,19)$. Slight infiltration with macrophages and no strong evidence of inflammation in odontogenic keratocysts can be a reason for moderate production and accumulation of TNF- $\alpha$ in the cysts found in our study.

OKC were previously histologically characterized by para or ortho-keratinized stratified squamosus epithelial lining with a high proliferatition activity with a tendency to recur $(10,20)$. Today the Word Health Organization has classified $\mathrm{OKC}$ as a benign tumour with odontogenic epithelium and mature fibrous stroma without odontogenic ectomesenchyme (3). Some authors belive that genetic alteration, including loss of heterozygosity of the tumour suppresor genes, support the OKC neoplastic nature $(1,4)$. Some clinical studies challenged this concept by demonstrating a good response to conservative approaches. A regression of calcifying odontogenic cysts, as benign odontogenic neoplasm, by marsupialization, was achieved (23). Imunohistochemistry studies show that IL-1 between other cytokines has a significant role in $\mathrm{OKC}$, and extensive expression of IL-1 was detected in endothelial cells and fibroblast, especially in subepithelial layers. Intracystic fluid from these cysts contained a higher concentration of IL-1 in comparison to IL- 6 and TNF- $\alpha$, which are very low (18). We also found lower values of TNF- $\alpha$ in $\mathrm{OKC}$ in comparion to radicular cysts.

One reason for the difference in cytokines can be the consequence of the diverse sensitivity of assays. We here simultaneously determined the concentration of TNF- $\alpha$ in two cyst types. Based on the identical clinical and histological diagnosis, we found a difference in these two cyst types. These clinical findings agree with previous investigations based on the molecular level showing that expression of mRNA by in situ hibridization for several proinflammatory cytokines have a varying degree of keratocytes, macrophages and fibroblast. Macrophages showed clear expression of mRNA for TNF- $\alpha$ and other cytokines in comparison to keratinocytes and gingival fibroblasts, which in partocular showed a lesser frequency of TNF- $\alpha$. (11).

As angiogenesis is an essential part of a variety of physiological and pathological processes, including inflammation and tumour progression and based on the consideration that these processes are controlled by numerous bioactive molecules, including TNF- $\alpha$ (25), we further estimated an association between the production of TNF- $\alpha$ and the degree of vascularisation in pericysts tissues. Based 
on this criteria we also founded that radicular cysts, which have more blood vessels per $\mathrm{mm}^{2}$ in comparison to keratocysts, exhibit a significant correlation with increase in the concentration of TNF- $\alpha$.

Together, these results show the difference between these two cystic types in the maxillofacial region based on several clinical parameters, including cyst size, protein concentration and the degree of opalescence of the cystic fluid, as well as on histological findings based on analyses of cystic wall thickness, the number of presenting inflammatory cells and the degree of vascularization in cyst walls. We believe that determining these cytokines simultaneously with other well established parameters can help for better clinical diagnoses.

\section{Acknowlegedgements}

This work is supported by grant from Ministry of Science of Republic Serbia.

\section{References}

1. Agaram NP, Collins B, Barnes L, Lomado D, Aldeeb D, Swalsky P et al. Molecular analysis to demonstrated that odontogenic keratocyst are neoplastic. Arch Pathol Lab Med, 2004;30:596-76.

2. Bando Y, Henderson B, Meghji S, Poole S, Harris M. Immunocytochemical localisation of inflammatory cytokines and vascular adhesion receptors in radicular cysts. J Oral Pathol Med. 1993;22:221-7.

3. Barnes L, Eveson JW, Reichard P, Sidransky D. World Health Organization classification of tumours. Pathology and Genetics. Head and Neck tumours. Lion IARC press; 2005.

4. Barreto DC, Bale AE, De Marco L, Gomez RS. Immunolocalisation of PTHC protein in odontogenic cyst and tumors. J Dent Res, 2002;81:757-60.

5. Bertolini DR, Nedwin GE, Bringman TS, Smith DD, Mundy GR. Stimulation of bone resorption and inhibition of bone formation in vitro by human tumor necrosis factor. Nature. 1986:319:516-18.

6. Birkedal-Hansen H. Role of cytokines and inflammatory mediators in tissue destruction. J Periodont Res. 1993;28:500-10.

7. Bletsa A, Berggreen E, Brudvik P. Interleukin-1 a and tumor necrosis factor- $\alpha$ expression during the early phases of orthodonic tooth movement in rats. Eur J Oral Sci, 2006114:423-9.

8. Colic M, Lukic A, Vucevic D, Milosavljevic P, Majstorovic I, Marjanovic M, Dimitrijevic J. Correlation between phenotypic chracteristics of mononuclea cells isolated from human periapical lesions and their in vitro production of $\mathrm{Th}$ and Th2 cytokines. Archives of Oral Biology, 2006;12:1120-30.
9. Danin J, Linder L, Lundqvist G, Wretlind B. Cytokines in periradicular lesion: efects of linezolid treatment. Orl Sur Oral Med Oral Pathol Oral Radiol Endod, 2003;96:492-8.

10. Garlet GP, Martins S Jr, Ferreira BR, Milanezi CM, Silva JS. Patterns of chemokines and chemokine receptors expression in different forms of human periodontal disease. J Periodontal Res. 2003;38:210-217.

11. Honma M, Hayakawa Y, Kosugi H, Koizumi F. Localisation of mRNA for inflammatory cytokines in radicular cyst tissue by in situ hybridization, and induction of inflammatory cytokines by human gingival fibroblast in responce to radicular cyst contents. J Oral Path Med. 1998;27:399-404.

12. Jurisic V, Bogdanovic G, Kojic V, Jakimov D, Srdic T. TNF- $\alpha$ effects on Raji cells at different cellular level estimated by various methods. Ann Haematology. 2006;85:86-94.

13. Jurisic V, Bogdanovic G, Srdic T, Jakimov D, Mrdjanovic J, Baltic M, Baltic V.V Modulation of TNF- $\alpha$ activity in tumor PC cells using anti-CD45 and anti CD95 monoclonal antibody. Cancer Lett. 2004;214:55-61.

14. Jurisic V, Spuzic I, Konjevic G. A comparison of NK cell activity with effects of TNF- $\alpha$ against K-562 cells, determined by LDH release assay. Cancer Lett. 1999;138:67-72.

15. Kakaranatza-Angelopoulon E, Nicolaton O. Odontogenic keratocysts. J Oral Maxillofac Surg 1990;48:593-9.

16. Kaneyama K, Segami N, Sun W, Sato J, Fujimura K. Analysis of tumor necrosis factor- $\alpha$, interleukin -6 , interleukin- $1 \beta$, soluble tumor necrosis factor receptors I and II, interleukin-6 soluble receptor, interleukin-1 soluble receptor type II, interleukin-1 receptor agonist and protein in the synovial fluid of patients with temporomandibular joint disorders. Oral Sur Oral Med Oral Pathol Oral Radiolo Endod. 2005:99:276-84.

17. Krammer IRH, Pindborg JJ, Shear M. Histological typing of odontogenic tumors, 2nd edn. Berlin, Heidelberg: Springer-Verlag, 1992;34-42.

18. Mattews JB, Mason GI, Browne RM. Epithelial cell markers and proliferating cells in odontogenic jaw cysts. J Pathol 1988:156:283-90.

19. Meghji S, Qureshi W, Henderson B, Harris M. The role of endotoxin and cytokines in the pathogenesis of odontogenic cysts. Arch Oral Biol 1996;41:523-31.

20. Ninomiya T, Kubota Y, Koji T, Shirasuna K. Marsupialization inhibits interleukin-1a expresion and epithelial cell proliferation i odontogenic keratocysts. J Oral Pathol Med 2002;31:526-33.

21. Ohsima M, Nishiyama T, Tokunaga K, Sato S, Maeno M, Otsuka K. Profiles of cytokine expression in radicular cyst-lining epithelium examinated by RT-PCR. J Oral Science. 2000;42:239-246.

22. Silva T, Lara VS, Rosa AL, Cuhna FQ. Cytokine and chemokine response of bone cells after dentil challenge in vitro. Oral Diseases. 2004;10:258-64.

23. Souza CG, Gomez RS. Odontogenic keratocyst: a benign cystic neoplasm? Oral Oncology, 2006 in press.

24. Stashenko P, Wang Cun Y, Tani-Ishii N, Yu SM. Pathogenesis of induced rat periapical lesions. Oral Surg Oral Med Oral Pathol. 1994;78:494-502.

25. Takeichi O, Saito I, Tsurumachi T, Moro I, Saito T. Expression of inflammatory cytokines genes in vivo by human alveolar bone derived polymorphonuclear leukocytes isolated from chronically inflamed sites of bone resortion. Calcified Tissue International, 1996;58:244-8.

26. Thomson BM, Mundy GR, Chambers TJ. Tumor necrosis factor- $\alpha$ and $\beta$ induce osteoblastic cells to stimulate osteoclastic bone resorption. J Immunology. 1987; 138:775-9.

\section{Corresponding author:}

Prof. Vladimir Jurisic, University of Kragujevac, School of Medicine, P.O. Box 124, 34000 Kragujevac, Serbia, e-mail: vdvd@mailcity.com 